\title{
Effects of plant diversity on primary production and species interactions in brackish water angiosperm communities
}

\author{
Tiina Salo*, Camilla Gustafsson, Christoffer Boström
}

Åbo Akademi University, Environmental and Marine Biology, Artillerigatan 6, 20520 Åbo, Finland

\begin{abstract}
Research on plant biodiversity and ecosystem functioning has mainly focused on terrestrial ecosystems, and our understanding of how plant species diversity and interactions affect processes in marine ecosystems is still limited. To investigate if plant species richness and composition influence plant productivity in brackish water angiosperm communities, a 14 wk field experiment was conducted. Using a replacement design with a standardized initial aboveground biomass, shoots of Zostera marina, Potamogeton filiformis and P. perfoliatus were planted on a shallow, sandy bottom in replicated monocultures and all possible species combinations. Response variables included aboveground and belowground biomass, shoot density, space occupation and porewater nutrients. To determine whether selection and/or complementarity controlled productivity, additive partitioning and $D_{i}$ were calculated. Richness effects were species-specific and only increased the biomass production of $P$. perfoliatus and tuber production of $P$. filiformis, while species composition generally had a stronger effect on biomass production. Additive partitioning indicated a positive complementarity effect for the aboveground biomass production in bicultures in general, while a positive net effect was found in the $P$. perfoliatus and $P$. filiformis biculture. Despite the absence of significant results for other treatments and plant variables, a trend of positive complementarity and negative selection effects were present. Plant diversity had no clear effect on sediment porewater nutrient concentrations, indicating weak richness effects on resource use.
\end{abstract}

KEY WORDS: Seagrass · Ecosystem function · Complementarity · Selection · Resource use

\section{INTRODUCTION}

As the relationship between biodiversity and ecosystem function (BEF; usually primary production) has mainly been based on experimental work in terrestrial plant ecosystems (e.g. Hooper \& Vitousek 1997, Hector et al. 1999, Loreau et al. 2001), it is still largely unknown to what extent terrestrial plant ecosystem processes are transferable to vegetated marine ecosystems (Solan et al. 2006). Experimental work manipulating different levels of diversity in marine systems have mostly shown significant effects of species richness. Specifically, these studies have shown the following: (1) in terms of primary producers and sessile animals, the effects of individual species are stronger than the role of diversity per $\mathrm{se}_{i}(2)$ diverse communities tend to be less variable, with enhanced resistance and faster recovery from disturbance compared to simple communities; and (3) diverse prey assemblages show higher resistance to predation compared to simple communities (Stachowicz et al. 2007). However, within BEF research, only about 10 field studies (e.g. Stachowicz et al. 2007) manipulating submerged macrophyte species (or genotypic) richness have been published, the majority being experiments with macroalgae, and only a couple of experiments have investigated effects of angiosperm (seagrass) species richness on ecosystem functioning (Parker et al. 2001, Moore \& Fairweather 2006). This is surprising given the strong research emphasis on plants within terrestrial BEF work and the similarities between aquatic and terrestrial angiosperm assemblages (Duarte 2000). 
Seagrass meadows provide vital functions (primary production, nutrient cycling), goods (habitat, food resources) and services (erosion control, indicator of coastal health), but are lost at accelerating rates due to human pressures (Duarte 2000, Orth et al. 2006). Half of the documented seagrass meadows are multispecific and contain 2 to 3 co-occuring species, while Asian seagrass meadows may consist of $>10$ co-occuring species (Duarte et al. 2000). Interestingly, the angiosperm assemblages in the Baltic Sea have comparable plant species (>10) and functional richness (Kautsky 1988), and multispecific meadows commonly contain 3 to 6 plant species of marine and limnic origin (Boström et al. 2003). However, due to the scarcity of field manipulations, the extent to which plant species diversity influences biological processes in seagrass meadows is still largely unexplored (Williams 1990, Kautsky 1991, Duarte et al. 2000).

Because plant species affect biogeochemical processes differently, the species diversity in an ecosystem influences the processes of that system (Tilman et al. 1997, Hooper 1998). If species are complementary, communities with a large repertoire of different functional groups should either utilize available resources more efficiently and thus show greater productivity compared to simple communities, i.e. a niche-differentiation effect (Tilman 1999, Loreau 2000), or enhance ecosystem-level processes due to beneficial intra- or interspecific interactions, i.e. facilitation (Cardinale et al. 2002, Srivastava \& Vellend 2005). However, while the relative role of individual species in a community may vary greatly, resource use and productivity is often expected to increase as diversity increases, simply because one or a few dominating species frequently affect a process the most, i.e. a selection effect (Hooper et al. 2005). Furthermore, species composition may affect processes in such a way that specific combinations of species have a higher impact on processes than other species combinations, though the number of species is the same (Stachowicz et al. 2007). Which of these mechanisms are important for ecosystem functioning of aquatic vegetated systems is still largely unknown (Duarte et al. 2000, Engelhardt \& Ritchie 2002), thus limiting our ability to predict consequences of species loss and disturbance, as well as the resistance and recovery capacity of multispecific plant assemblages.

While work in terrestrial grasslands suggests that species with, for example, differing rooting depths and nutrient requirements should be able to coexist, exploit resources more fully and show higher productivity (Fargione \& Tilman 2005), there is still limited information on the influence of plant diversity on resource use in marine environments.

The main aim of the present study was to investigate in situ how angiosperm species richness and composition influence plant primary production and resource use. We assembled plots of the following 3 species: Zostera marina L., Potamogeton perfoliatus L. and P. filiformis Pers. These species differ markedly in terms of morphological traits, biomass allocation patterns and productivity (Kautsky 1988, 1991), and are considered able to coexist in the Baltic Sea due to differential resource use (Kautsky 1991). Thus, in addition to species richness, the number of different functional types was also manipulated, which allows for a better understanding of which species traits are important in competitive and/or complementary interactions (Tilman et al. 1997). Furthermore, as all combinations of the plant species were manipulated in a replicated field experiment, the relative importance of complementarity and selection effects in angiosperm assemblages was also assessed.

We hypothesized that species complementarity would result in more efficient resource use (decreased sediment nutrient pool concentrations) and higher production in mixed cultures compared to monocultures, while a positive selection effect would be present in mixtures containing Potamogeton perfoliatus and/or Zostera marina due to their high production capacity. In terms of spatial partitioning, Z. marina and P. perfoliatus were hypothesized to show extensive lateral spread, while $P$. filiformis was expected to show moderate space occupation capacity (see Kautsky 1988).

\section{MATERIALS AND METHODS}

Study area and site characteristics. The non-tidal northern Baltic Sea is characterized by low salinity (6 to 8 PSU), strong seasonal temperature fluctuations $\left(0\right.$ to $20^{\circ} \mathrm{C}$ ) and mixed macrophyte communities (Kautsky 1988, Kautsky \& Kautsky 2000). The present study was conducted in the Archipelago Sea, SW Finland, where submerged sandbanks support diverse macrophyte assemblages (Boström et al. 2006). The average water depth at the study site (Fårö Island, 59 55.219' N, $21^{\circ} 47.711^{\prime} \mathrm{E}$ ) was $1.3 \mathrm{~m}$, and the area is relatively exposed to NE winds. The nearshore area is mostly unvegetated and consists of a sediment dominated by fine $(\sim 70 \% 0.125 \mathrm{~mm})$ to very fine $(\sim 5 \% 0.0062 \mathrm{~mm})$ sand with low $(<0.5 \%)$ organic content. A seagrass meadow dominated by eelgrass Zostera marina, sago pondweed Potamogeton pectinatus L. and perfoliate pondweed $P$. perfoliatus grows from 2 to $6 \mathrm{~m}$ depth. Slender-leaved pondweed $P$. filiformis and horned pondweed Zannichellia palustris L. grow both within the meadow and in monocultures bordering the meadow, while Eurasian water-milfoil Myriophyllum spicatum L. and ditchgrass Ruppia cirrhosa (Petagna) Grande occur patchily within the meadow. During the present study, the water temperature ranged between $10^{\circ} \mathrm{C}$ (October) and $20^{\circ} \mathrm{C}$ (July). 
Experimental setup and sampling. The plant species used in the experiment were Zostera marina, Potamogeton filiformis and $P$. perfoliatus. A replacement design with a standardized aboveground biomass was used (Harper 1977). Thus, the total start aboveground biomass in all plots was $30 \mathrm{~g}$ wet weight (WW), i.e. $30 \mathrm{~g}$ of a species in monocultures, $15 \mathrm{~g}$ of each component species in bicultures and $10 \mathrm{~g}$ of each component species in the triculture. This total biomass corresponded to 21, 26 and 37 shoots for Z. marina, P. filiformis and $P$. perfoliatus, respectively. Plants were grown in all possible combinations ( 7 treatments) in a randomized block design with 4 replicates of each treatment. The distance between plots was $2 \mathrm{~m}$ and the distance between blocks was $2.5 \mathrm{~m}$. Two weeks prior to the start of the experiment, scattered plants and stones were removed from the unvegetated area.

When starting the experiment, experimental plants (ramets) were collected from the study site and transplanted within $8 \mathrm{~h}$. To estimate the initial dry weight (DW) of aboveground and belowground biomass, 20 to 30 randomly chosen plants of each species were set aside. To standardize plant spacing and prevent uprooting, plants were carefully tied to a flexible 30 $\times 30 \mathrm{~cm}$ plastic grid (mesh size $30 \mathrm{~mm}$ ). In mixed plots, individual component species were tied in a non-random, even spatial pattern, avoiding grouping of conspecifics. Plants were kept submerged during the handling process. Experimental units were planted 3 to $5 \mathrm{~cm}$ into the sediment using SCUBA diving. In addition, empty grids used as controls for sediment nutrients were positioned randomly within each block $(\mathrm{n}=4)$. The experiment ran for $14 \mathrm{wk}$ (10 July to 21 October 2007), representing one growing season.

To estimate the potential influence of plant species richness on organic matter deposition and mineralization, sediment cores (diameter $2.5 \mathrm{~cm}$, depth $5 \mathrm{~cm}$ ) were taken for sediment $\mathrm{C}: \mathrm{N}$ determination 1 mo prior to the termination of the experiment (11 September). The C:N samples were sieved $(0.5 \mathrm{~mm})$, dried $\left(105^{\circ} \mathrm{C}\right.$, $24 \mathrm{~h}$ ) and ground, and subsequently analyzed in a certified lab according to the method of Kristensen \& Andersen (1987) with an elemental analyzer (CarloErba 1100EA). Three days prior to the termination of the experiment, (i.e. after $\sim 13 \mathrm{wk}$, when plots had reached maximum development), the space occupation capacity through clonal growth of each species in each plot was assessed by measuring the maximum spatial expansion (cm) from the initial plot edge. All plots were also sampled for sediment porewater nutrients using Rhizon soil moisture samplers (type SMS: length $100 \mathrm{~mm}, \varnothing 2.5 \mathrm{~mm}$, Eijelkamp Agrisearch Equipment) connected to $125 \mathrm{ml}$ vacuum bottles. The sampler was inserted to 10 to $12 \mathrm{~cm}$ depth in the center of each plot (thus covering the entire root layer) and connected to a vacuum bottle with a PVC tube and a syringe. Porewater samples were kept in the dark and deep-frozen $\left(-20^{\circ} \mathrm{C}\right)$ upon arrival at the laboratory, and analyzed for $\mathrm{NH}_{4}{ }^{+}$and $\mathrm{PO}_{4}{ }^{3-}$ in a certified lab. In addition, water column nutrient samples (total $\mathrm{N}$, total $\mathrm{P}, \mathrm{NH}_{4}{ }^{+}, \mathrm{PO}_{4}{ }^{3-}$ ) were taken from the experimental area on 20 August, 5 September and 2 and 21 October, and treated as outlined above.

At the termination of the experiment, all plant material including belowground parts in each plot was harvested (except for one replicate of the Potamogeton perfoliatus monoculture which was lost), transported to the laboratory and deep frozen $\left(-18^{\circ} \mathrm{C}\right)$. In the laboratory, samples were thawed and plants were carefully cleansed from animals, algae, etc. The number of shoots, as well as the aboveground (shoots) and belowground (rhizomes, roots) biomass, was determined for each species. The biomass (DW) was determined on an analytical scale after drying to constant weight (48 h, $60^{\circ} \mathrm{C}$ ). In addition, the number and biomass (DW) of overwintering organs was determined for all $P$. filiformis (tubers) and $P$. perfoliatus (turions) ramets. To compensate for the initial differences in planting biomasses, tuber and turion abundances were multiplied by 2 and 3 in bicultures and tricultures, respectively, see Engelhardt \& Ritchie (2002).

Data analysis. To determine the mechanisms explaining observed patterns, additive partitioning of biodiversity effects was used to assess the importance of selection (SE), complementarity (CE) and net biodiversity effect (NE) in mixed cultures (Loreau \& Hector 2001). In addition, $D_{i}$ was calculated to describe how the yield of a species in polyculture differs from its expected yield (Loreau 1998):

$$
D_{i}=\left(O_{i}-E_{i}\right) / E_{i}
$$

where $O_{i}$ and $E_{i}$ are the observed and expected yields of species $i$, respectively.

One-way ANOVA and regression analysis were performed to detect differences in plant variables. Prior to analysis, Kolmogorov-Smirnov and Levene's tests were used to test if data fulfilled assumptions for parametric testing. In some cases data, were logtransformed to fulfill these assumptions. In case of heteroscedasticity and for calculations involving percentage values $>100$, a non-parametric Kruskal-Wallis test accompanied by a Mann-Whitney $U$-test was used. Additive partitioning and $D_{i}$ were calculated for aboveground, belowground and total biomass production. The calculated indices were tested against a value of 0.0 with a 1 -sample $t$-test. To correct for multiple comparisons, results from the $t$-tests were corrected using the Dunn-Sidák method (Sokal \& Rohlf 1994). All means are given \pm SE. 


\section{RESULTS}

\section{Biomass allocation patterns and species composition effects}

The plant communities differed significantly from each other in terms of aboveground, belowground and total biomass $(H=25.38, \mathrm{p}=0.017 ; H=16.01, \mathrm{p}=0.014$ and $H=15.44, \mathrm{p}=0.017$, respectively, Fig. 1$)$. The number of shoots per plot varied between $14 \pm 3$ (Potamogeton perfoliatus monoculture) and $218 \pm 31$ ( $P$. filiformis monoculture) (Fig. 1a). The final accumulated aboveground biomass ranged between $0.3 \pm 0.1$ ( $P$. perfoliatus monoculture) and $4.3 \pm 0.4 \mathrm{~g} \mathrm{DW}$ (biculture of Zostera marina and P. filiformis), while belowground biomasses were generally higher and ranged from $1.2 \pm 0.3$ (P. perfoliatus monoculture) to $6.0 \pm 1.6 \mathrm{~g}$ DW (Z. marina monoculture) (Fig. 1b,c). The total plot biomass ranged from $1.5 \pm 0.3$ ( $P$. perfoliatus monoculture) to a maximum of $10 \pm 2.6 \mathrm{~g}$ DW ( $Z$. marina monoculture) (Fig. 1d). As root:shoot (R:S) ratios did not differ for individual species across treatments, ratios were pooled. Thus, P. perfoliatus and Z. marina invested most in belowground biomass, with R:S ratios of $2.9 \pm$ 0.1 and $1.5 \pm 0.1$, respectively, while $P$. filiformis allocated most of its production to shoots (R:S ratio of $0.9 \pm$ 0.03). For $Z$. marina, the spatial expansion in terms of clonal growth ranged between $25.8 \pm 4.2$ (biculture with $P$. perfoliatus) and $32.8 \pm 2.8 \mathrm{~cm}$ (monoculture), and for $P$. perfoliatus from $18.3 \pm 4.4$ (biculture with $Z$. marina) to $25.0 \pm 7.6 \mathrm{~cm}$ (biculture with $P$. filiformis). The highest space occupation capacity was recorded for $P$. filiformis $(42.3 \pm 6.2$ [triculture] to $62.5 \pm 2.2 \mathrm{~cm}$ [monoculture]).

Species composition had a strong effect on the community performance. When present, Zostera marina significantly increased the belowground and total biomass production of the plant communities by 42 and $34 \%$, respectively (Table 1$)\left(F_{1,10}=8.793, \mathrm{p}=0.014\right.$; $\left.F_{1,10}=7.142, \mathrm{p}=0.023\right)$. Similarily, Potamogeton filiformis contributed significantly to the shoot density, with $160 \%$ more shoots in communities with the species present $\left(F_{1,10}=73.302, \mathrm{p}<0.001\right)$, while the presence of $P$. perfoliatus led to $35 \%$ lower aboveground biomasses $\left(F_{1,10}=15.876, \mathrm{p}=0.003\right)$.

\section{Temporal changes in plant communities and richness effects}

When comparing the performance of individual species in different mixtures, the relative (\%) temporal change in shoot density (ramet production), aboveground, belowground and total biomass production
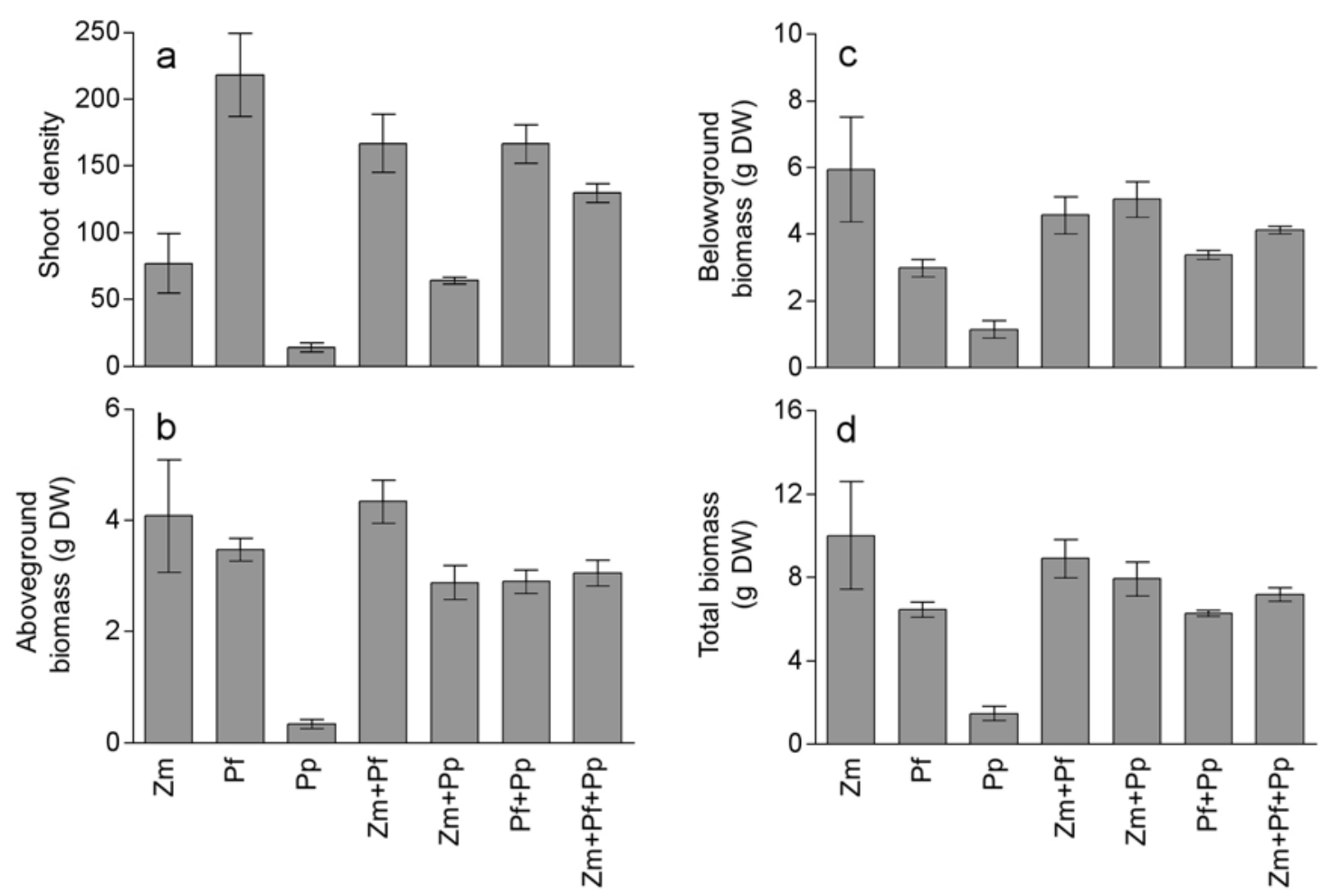

Fig. 1. Zostera marina, Potamogeton filiformis and P. perfoliatus. Mean (a) shoot densities, (b) aboveground biomass, (c) belowground biomass and (d) total biomass in the assembled plant communities. Zm: Z. marina; Pf: P. filiformis; Pp: P. perfoliatus. Error bars are $\pm \mathrm{SE}$ 
Table 1. Zostera marina, Potamogeton filiformis and P. perfoliatus. Mean $( \pm$ SE) shoot density, aboveground biomass, belowground biomass and total biomass in the presence and absence of each component species in the experimental communities. Asterisks indicate significant differences in community performance in the presence versus absence of a component species: ${ }^{*} \mathrm{p}<0.05_{i}{ }^{* *} \mathrm{p}<0.005$. DW: dry weight

\begin{tabular}{|llcccc|}
\hline Species & Shoot density & $\begin{array}{c}\text { Aboveground } \\
\text { biomass (g DW) }\end{array}$ & $\begin{array}{c}\text { Belowground } \\
\text { biomass (g DW) }\end{array}$ & $\begin{array}{c}\text { Total biomass } \\
\text { (g DW) }\end{array}$ \\
\hline Z. marina & Presence & $115.6 \pm 21.9$ & $3.6 \pm 0.4$ & $4.8 \pm 0.4^{*}$ & $8.4 \pm 0.6^{*}$ \\
& Absence & $117.0 \pm 14.5$ & $2.9 \pm 0.2$ & $3.4 \pm 0.1$ & $6.3 \pm 0.1$ \\
P. filiformis & Presence & $166.9 \pm 12.1^{* *}$ & $3.6 \pm 0.3$ & $4.0 \pm 0.3$ & $7.5 \pm 0.7$ \\
& Absence & $64.3 \pm 2.8$ & $2.9 \pm 0.3$ & $5.0 \pm 0.5$ & $7.9 \pm 0.8$ \\
P. perfoliatus & Presence & $115.5 \pm 20.5$ & $2.9 \pm 0.2^{* *}$ & $4.2 \pm 0.4$ & $7.1 \pm 0.5$ \\
& Absence & $167.0 \pm 21.8$ & $4.3 \pm 0.4$ & $4.6 \pm 0.6$ & $8.9 \pm 0.9$ \\
\hline
\end{tabular}

generally showed minor differences (Fig. 2). Potamogeton filiformis had the lowest production in monocultures, though this was non-significant, while $P$. perfoliatus performed significantly better in mixed cultures in terms of shoot density and aboveground biomass investment $(H=9.7, \mathrm{p}=0.021$ and $H=9.9, \mathrm{p}=$ 0.019 , respectively). In particular, $P$. perfoliatus had a significantly higher ramet production in tricultures than in bicultures with $P$. filiformis $(U=0.000, \mathrm{p}=$ 0.029, Fig. 2). Compared to its starting density, P. filiformis increased its shoot density by 1 order of magnitude (biculture with $P$. perfoliatus), while $P$. perfoliatus and Zostera marina reached, at maximum, $\sim 0.5$ and $>3$ times their initial densities, respectively (Fig. 2a). The relative increase in aboveground biomass followed the shoot density pattern (Fig. 2b), while the change in belowground biomass was surprisingly uniform between species and across treatments (Fig. 2c).

When measuring the relative (\%) temporal change in terms of shoot density and aboveground biomass production at the plot level in mixed cultures, the greatest change was found in the biculture of Zostera marina and Potamogeton filiformis (Fig. 3a,b). In terms of belowground biomass, the greatest change was recorded in the biculture of $Z$. marina and $P$. perfoliatus (Fig. 3c), while in terms of total biomass the biculture

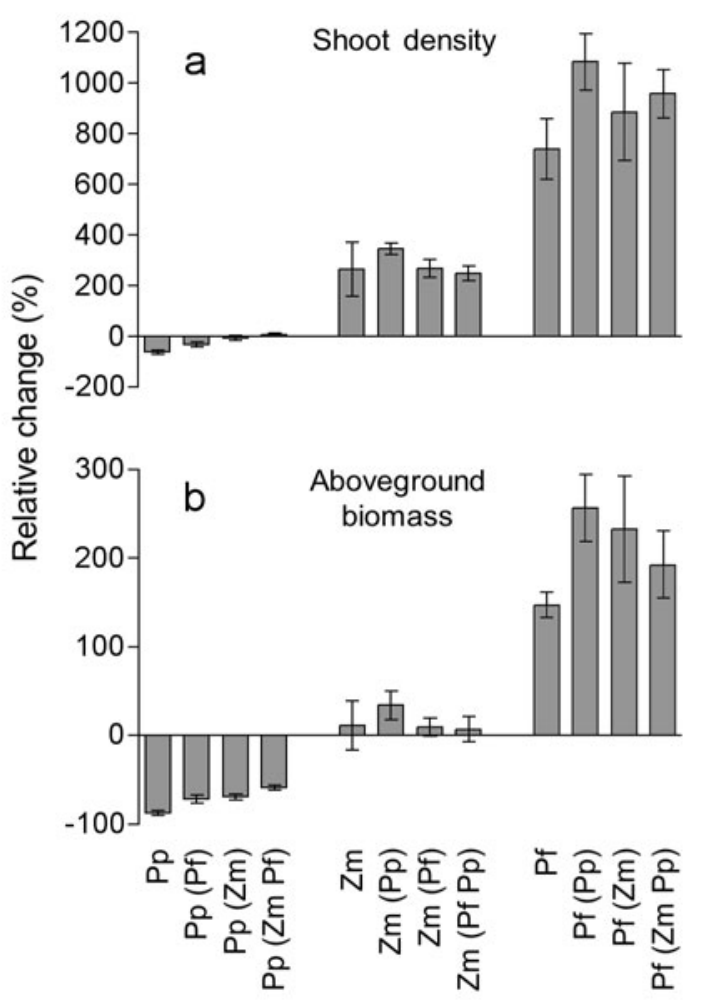

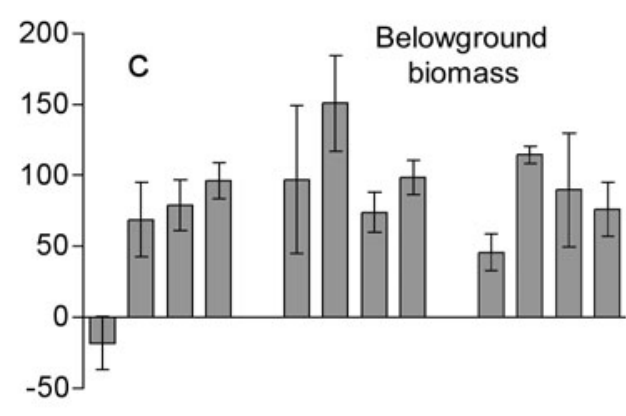

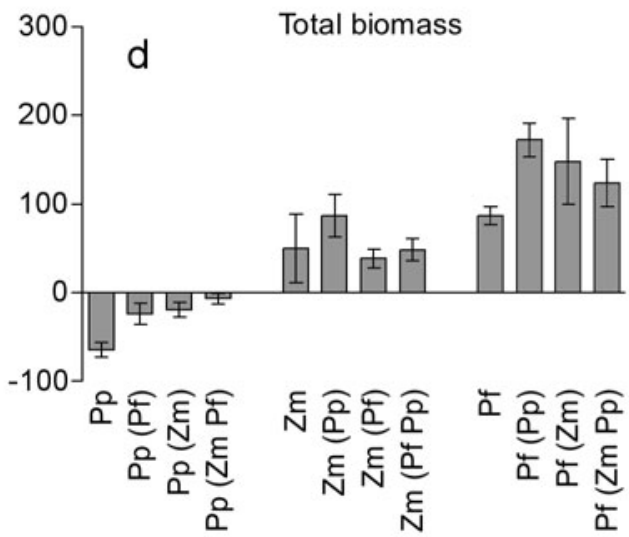

Fig. 2. Zostera marina, Potamogeton filiformis and P. perfoliatus. Relative (\%) change in (a) shoot density, (b) aboveground biomass, (c) belowground biomass and (d) total biomass. Species in parentheses indicate other species present in the culture but not represented by the bars. Species abbreviations as in Fig. 1. Data are means $\pm \mathrm{SE}$ 

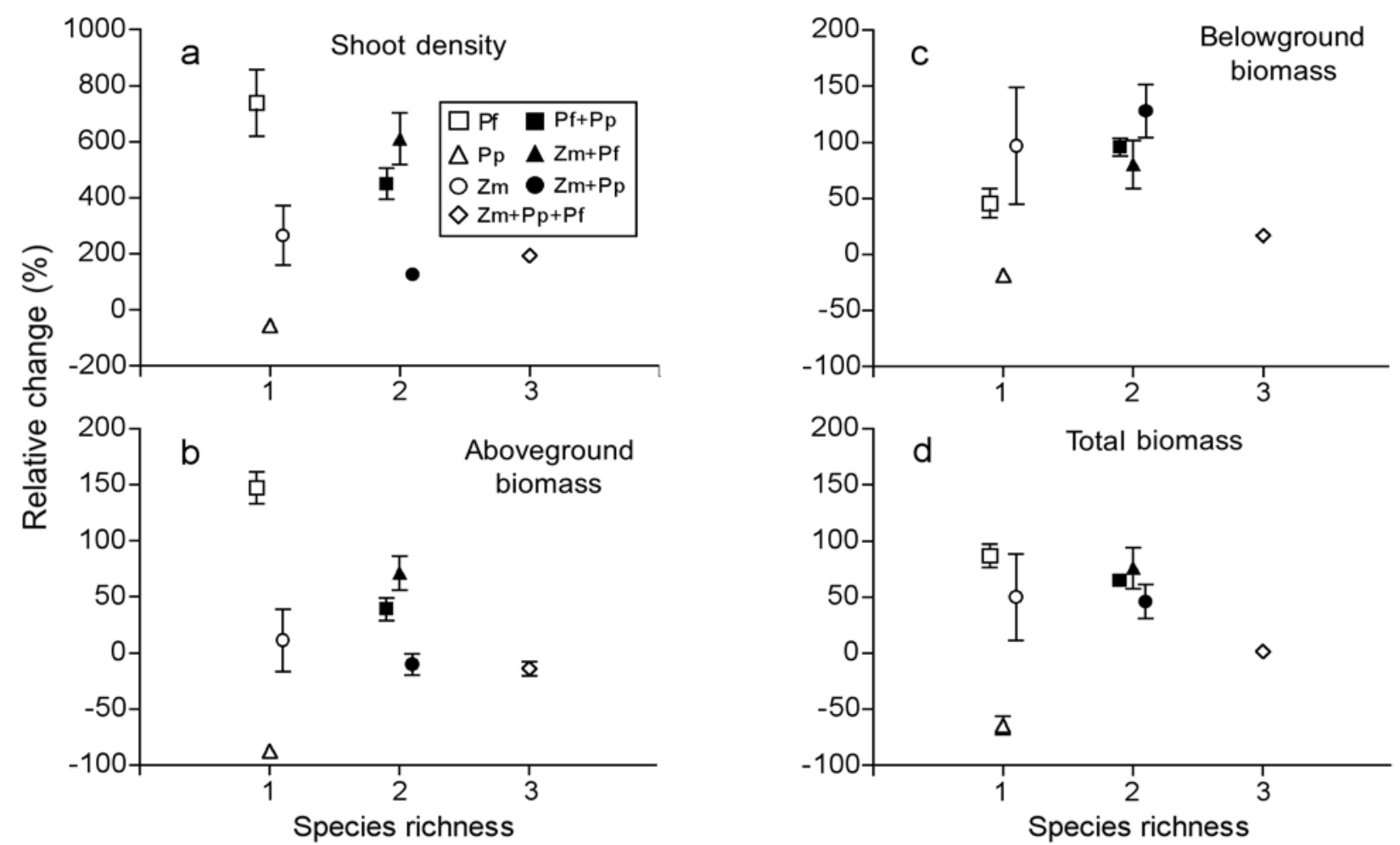

Fig. 3. Zostera marina, Potamogeton filiformis and P. perfoliatus. Relative (\%) change in (a) shoot density, (b) aboveground biomass, (c) belowground biomass and (d) total biomass in relation to species richness. Species abbreviations as in Fig. 1. Data are means \pm SE (not visible for all treatments due to scale)

of Z. marina and P. filiformis expressed the greatest relative change (Fig. 3d). The different treatments differed significantly from each other in terms of shoot density $(H=22.1, \mathrm{p}=0.001)$, aboveground biomass $(H=22.3, \mathrm{p}=0.001)$, belowground biomass $(H=16.0$, $\mathrm{p}=0.014)$ and total biomass $(H=15.6, \mathrm{p}=0.016)$.

For Potamogeton perfoliatus, species richness enhanced all biomass production variables, while $P$. filiformis and Zostera marina showed nonlinear relation-

Table 2. Zostera marina, Potamogeton filiformis and P. perfoliatus. Simple linear regression results for responses to increasing plant species richness in the field experiment

\begin{tabular}{|llccrc|}
\hline Species & Plant variable & $\mathrm{df}$ & $F$ & $\mathrm{p}$ & $\mathrm{r}^{2}$ \\
\hline P. perfoliatus & Shoot density & 1,13 & 20.7 & 0.001 & 0.610 \\
& Aboveground biomass & 1,13 & 12.88 & 0.003 & 0.500 \\
& Belowground biomass & 1,13 & 34.35 & $<0.001$ & 0.730 \\
& Total biomass & 1,13 & 17.26 & 0.001 & 0.570 \\
P. filiformis & Shoot density & 1,14 & 0.41 & 0.843 & 0.003 \\
& Aboveground biomass & 1,14 & 0.03 & 0.867 & 0.002 \\
& Belowground biomass & 1,14 & 0.001 & 0.972 & 0.000 \\
& Total biomass & 1,14 & 0.002 & 0.964 & 0.000 \\
& Shoot density & 1,14 & 1.3 & 0.274 & 0.085 \\
& Aboveground biomass & 1,14 & 0.56 & 0.469 & 0.038 \\
& Belowground biomass & 1,14 & 0.76 & 0.399 & 0.051 \\
& Total biomass & 1,14 & 0.68 & 0.425 & 0.046 \\
\hline
\end{tabular}

ships with increasing species number (Table 2, Fig. 4). The number of tubers and turions of $P$. filiformis and $P$. perfoliatus, respectively, correlated positively with species richness (tubers: $F_{1,14}=8.882, \mathrm{p}=0.010, \mathrm{r}^{2}=0.388$; turions: $F_{1,13}=5.631, \mathrm{p}=0.034, \mathrm{r}^{2}=0.302$ ) (Fig. 5).

\section{Additive partitioning and $D_{i}$}

The aboveground, belowground and total biomass production in biculture treatments showed similar, but non-significant, responses with positive $\mathrm{CE}$ and negative SE resulting in a positive NE. However, the biculture consisting of Potamogeton filiformis and P. perfoliatus showed a significant positive NE for total biomass production ( $t$-test, $\mathrm{p}=0.004)$. The triculture treatment also showed non-significant positive CE and negative SE for all the measured plant variables, resulting in a negative NE (Fig. 6). In terms of species richness, bicultures showed a significant positive CE for aboveground biomass ( $t$-test, $\mathrm{p}=0.016$ ) (Fig. 6), while the other plant variables were non-significant and followed the same trend of positive $\mathrm{CE}$ and negative $\mathrm{SE}$ as described above. 

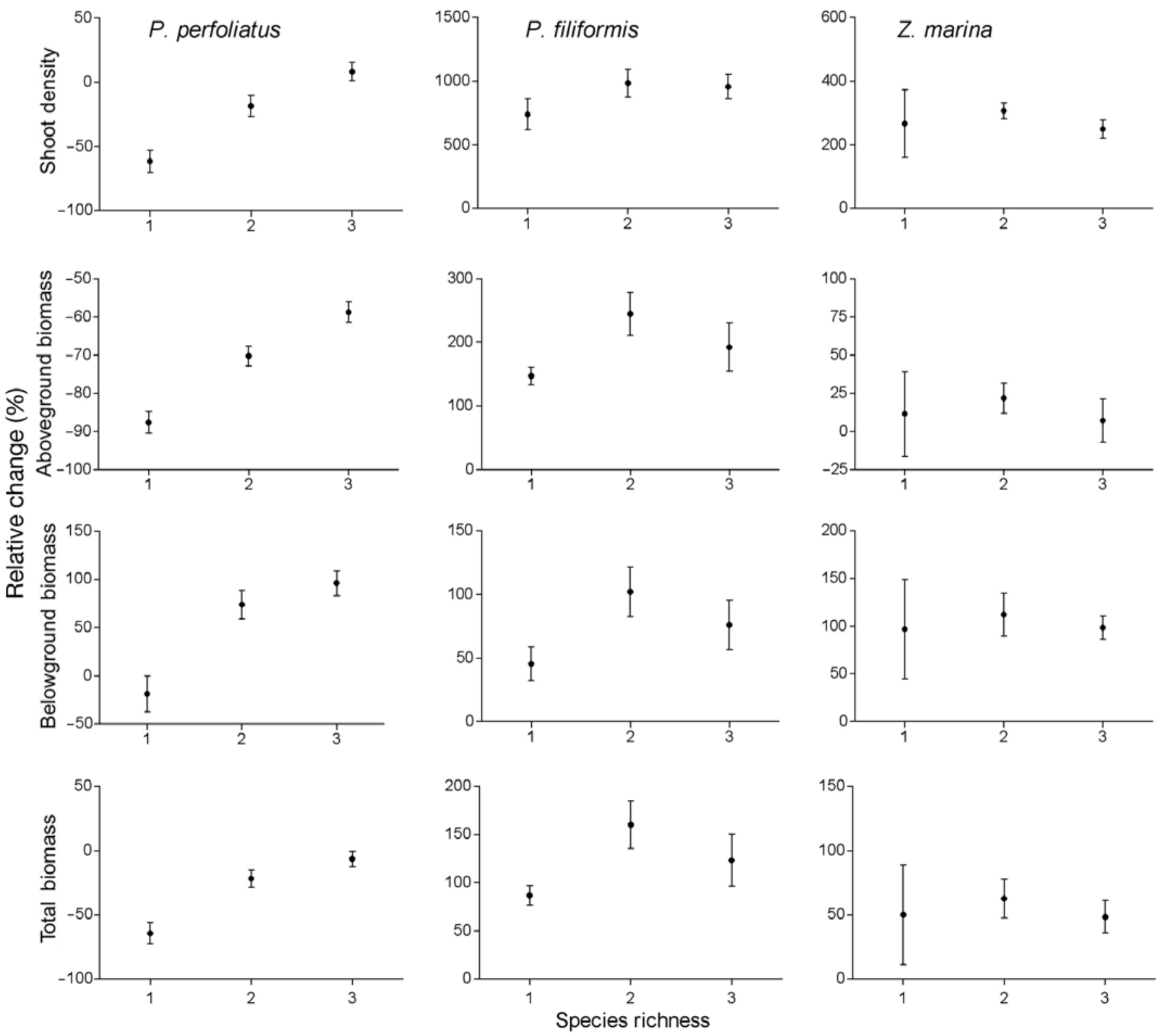

Fig. 4. Zostera marina, Potamogeton filiformis and P. perfoliatus. Relative (\%) change in aboveground biomass, belowground biomass and total plant biomass and shoot density for each species in relation to species richness. Data are means $\pm \mathrm{SE}$

All treatments showed positive $D_{i}$, values indicating that all species performed better in mixes than expected (Table 3). However, none of these $D_{i}$ values were statistically significant.

\section{Sediment and water column nutrients}

The C:N ratio was low in all treatments including controls, and ranged from 3.9 to 4.5 , with no richness effects $\left(F_{1,29}=4.0, \mathrm{p}=0.055, \mathrm{r}^{2}=0.121\right)$. The control plots revealed significantly higher porewater $\mathrm{NH}_{4}{ }^{+}$concentra- tions compared to other treatments $\left(F_{7,22}=6.5, \mathrm{p}<\right.$ 0.001 ), while none of the individual plant treatments differed in terms of porewater nutrient concentrations. Among plant treatments, the $\mathrm{NH}_{4}{ }^{+}$concentration ranged between $12.6 \pm 4.1$ (Potamogeton filiformis monoculture) and $22.3 \pm 9.0 \mu \mathrm{M}$ (triculture). In terms of richness, the $\mathrm{NH}_{4}{ }^{+}$concentration was highest in the control treatments $(67.2 \pm 13.5 \mu \mathrm{M})$, lowest in monocultures $(14.4 \pm 2.5 \mu \mathrm{M})$ and increased somewhat with increasing species richness (quadratic regression: $F_{2,27}=15.95, \mathrm{p}<0.001, \mathrm{r}^{2}=0.54$, Fig. 7a). The porewater $\mathrm{PO}_{4}{ }^{3-}$ concentration ranged between $1.91 \pm 0.78$ (Zostera marina and $P$. perfoliatus 

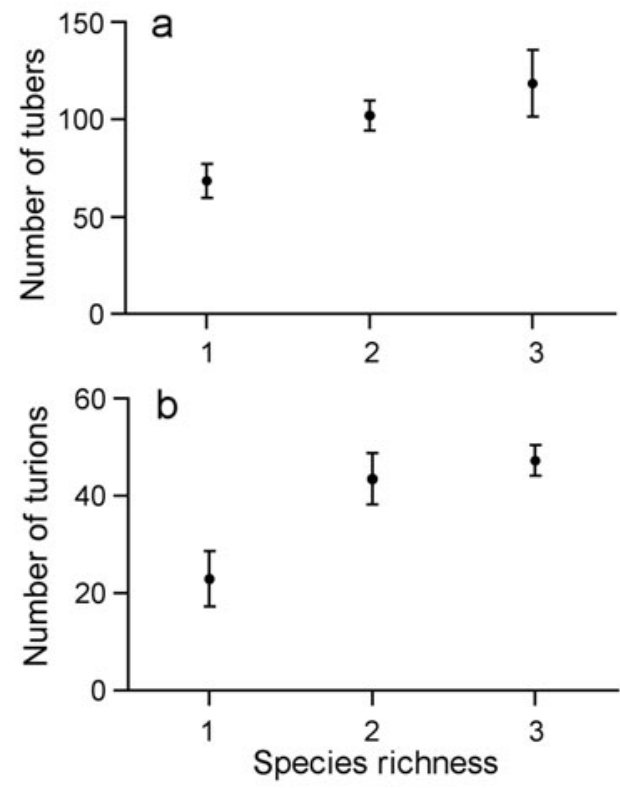

Fig. 5. Potamogeton filiformis and P. perfoliatus. Compensated number of (a) tubers ( $P$. filiformis) and (b) turions ( $P$. perfoliatus) in relation to species richness. Data are means $\pm \mathrm{SE}$

biculture) and $0.63 \pm 0.19 \mu \mathrm{M}(P$. perfoliatus monoculture), but did not differ between treatments $\left(F_{7,22}=0.89\right.$, $\mathrm{p}=0.53)$. The $\mathrm{PO}_{4}{ }^{3-}$ concentration in the controls was $1.45 \pm 0.55 \mu \mathrm{M}$. No relationship between species richness and porewater $\mathrm{PO}_{4}{ }^{3-}$ concentration was found $\left(F_{1,28}=0.05, \mathrm{p}=0.82, \mathrm{r}^{2}=0.002\right.$, Fig. $\left.7 \mathrm{~b}\right)$. Compared to the sediment nutrient pools, water column nutrient concentrations were substantially lower and ranged during the season from 0.17 to $0.38 \mu \mathrm{M}$ (total $\mathrm{N}$ : 17.1 to $24.3 \mu \mathrm{M}$ ) and 0.05 to $0.17 \mu \mathrm{M}$ (total P: 0.59 to $0.64 \mu \mathrm{M}$ ) for $\mathrm{NH}_{4}{ }^{+}$ and $\mathrm{PO}_{4}{ }^{3-}$, respectively.

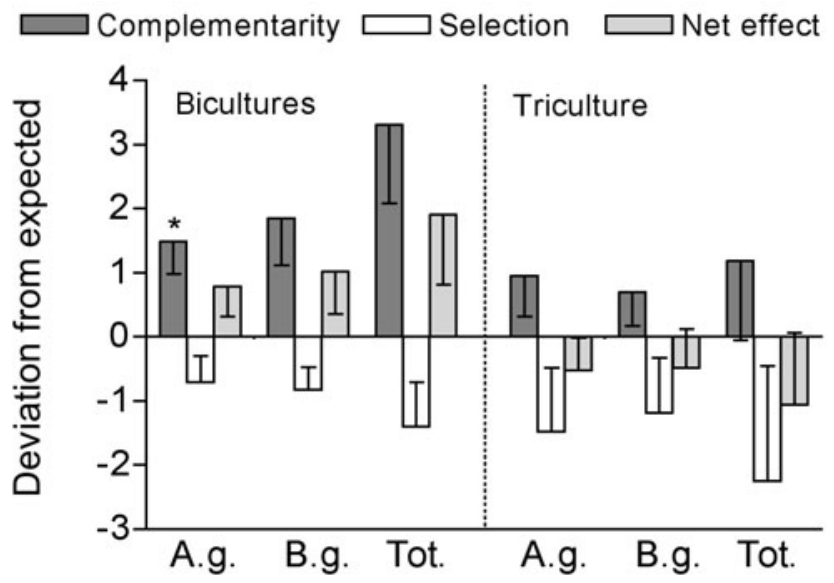

Fig. 6. Zostera marina, Potamogeton filiformis and P. perfoliatus. Additive partitioning of aboveground biomass (A.g.), belowground biomass (B.g.) and total biomass (Tot.) in the bicultures and the triculture. Asterisk denotes a significant $(p=0.016)$ effect. Data are means and SE
Table 3. Zostera marina, Potamogeton filiformis and P. perfoliatus. Species performance $\left(D_{i}\right.$, mean $\left.\pm \mathrm{SE}\right)$ calculated for aboveground, belowground and total biomass production in mixed cultures. Asterisks in parentheses indicate significant differences from $0.0(\mathrm{p}<0.05)$ that disappeared after correcting for multiple comparisons. Zm: Zostera marina; Pf: Potamogeton filiformis; Pp: P. perfoliatus

\begin{tabular}{|llll|}
\hline Plant culture & $\begin{array}{c}\text { Aboveground } \\
\text { biomass }\end{array}$ & $\begin{array}{c}\text { Belowground } \\
\text { biomass }\end{array}$ & $\begin{array}{c}\text { Total } \\
\text { biomass }\end{array}$ \\
\hline Zm bicultures & $0.82 \pm 0.68$ & $1.00 \pm 0.82$ & $0.92 \pm 0.76$ \\
Zm triculture & $0.23 \pm 0.37$ & $0.51 \pm 0.65$ & $0.39 \pm 0.53$ \\
Pf bicultures & $0.43 \pm 0.19$ & $0.39 \pm 0.12\left({ }^{*}\right)$ & $0.40 \pm 0.14\left({ }^{*}\right)$ \\
Pf triculture & $0.21 \pm 0.21$ & $0.26 \pm 0.20$ & $0.22 \pm 0.19$ \\
Pp bicultures & $1.56 \pm 0.50\left(^{*}\right)$ & $1.27 \pm 0.45\left(^{*}\right)$ & $1.34 \pm 0.46\left(^{*}\right)$ \\
Pp triculture & $2.77 \pm 1.31$ & $1.72 \pm 0.95$ & $1.96 \pm 1.03$ \\
\hline
\end{tabular}

\section{DISCUSSION}

\section{Species interactions among rooted macrophytes}

The results obtained in the present study indicate that ecosystem processes in macrophyte assemblages are influenced by species composition. Among the species tested, positive $\mathrm{CE}$ and negative SE were recorded, thus leading to both a positive and negative NE depending on the treatment. While complementarity did not lead to a significant increase in resource use, facilitation is suggested to occur in the communities. We found no increase in total primary production with increasing plant richness. The richness effects recorded were weak and species-specific, i.e. an enhanced biomass production of Potamogeton perfoliatus and tuber production of $P$. filiformis, while Zostera marina appeared unaffected by the presence of other species. To our knowledge, this is the first manipulative aquatic in situ BEF study on interactions and resource use among angiosperm species.

In marine ecosystems, the relationship between macrophyte richness and primary productivity is strongly influenced by species composition, while richness effects are generally non-existent or weak (Stachowicz et al. 2007). In the present study, richness effects were only found for Potamogeton perfoliatus, which increased its shoot density and biomass production with increasing species richness. In addition, the tuber production of $P$. filiformis correlated positively with species number. Richness effects may be dependent on the duration of the experiment. In accordance with the present study, short-term terrestrial grassland experiments have not found a relationship between species richness and primary production (Naeem et al. 1996, Weigelt et al. 2007), while positive correlations have emerged from long-term studies (Hector et al. 1999, Roscher et al. 2007). Since the production of previous years may alter 

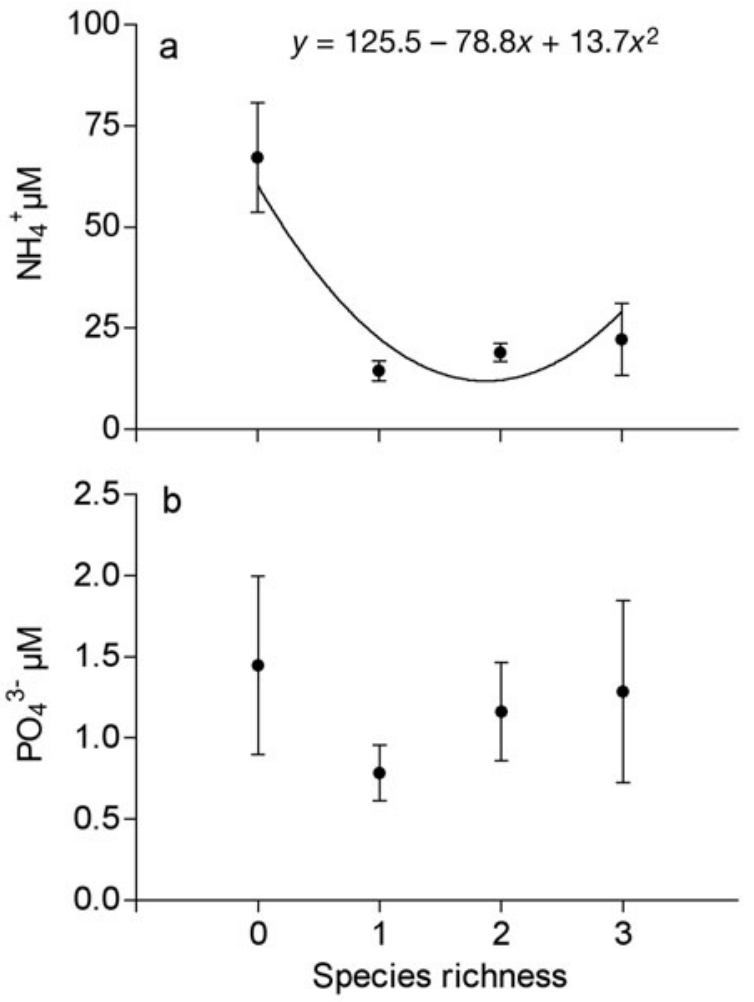

Fig. 7. Zostera marina, Potamogeton filiformis and P. perfoliatus. Relationships between sediment porewater nutrient concentration and plant species richness. (a) $\mathrm{NH}_{4}{ }^{+}$(quadratic regression: $\mathrm{p}<0.001, \mathrm{r}^{2}=0.54$ ). (b) $\mathrm{PO}_{4}{ }^{3-}$ (no relationship was found). Data are means $\pm \mathrm{SE}$

long-term patterns in plant communities, short-term experiments may fail to detect species complementarity (Hooper \& Dukes 2004). Alternatively, biodiversity effects in marine plant communities may, compared to terrestrial ecosystems, be subordinated in comparison to more influential limiting factors such as irradiance, waves and currents, nutrients, epiphytes and sediment characteristics. Thus, in order to fully capture potential biodiversity effects in aquatic plant communities, future manipulations should preferentially span several years and include different environmental settings (Cardinale et al. 2000, 2007).

In accordance with macroalgal BEF studies (Bruno et al. 2005, 2006), compositional effects had a strong effect on primary production. For example, Zostera marina enhanced both the total community and belowground production, while Potamogeton filiformis significantly contributed to increased ramet production. Similarily, in tropical seagrass systems, the community composition is thought to be of greater importance for the maintenance of ecosystem functions than the number of species per se (Duarte 2000).

The positive CE recorded in the present study indicates the presence of either facilitation or niche parti- tioning (Bertness \& Callaway 1994, Loreau \& Hector 2001, Duffy 2006). Our findings are supported by the results of Kautsky (1991), who observed complementarity between Potamogeton filiformis and P. perfoliatus and suggested this was due to the differences in rooting depths. Surprisingly, the sediment porewater nutrient concentrations were higher in the biculture and triculture treatments compared to the monocultures. Thus, complementary nutrient use is unlikely to explain this positive effect. Other forms of positive interactions, e.g. enhanced oxygen release to the rhizosphere (Caffrey \& Kemp 1991, Callaway \& King 1996) or increased nutrient use efficiency (van Ruijven \& Berendse 2005), may possibly explain this result.

The frequent occurrences of negative SE among treatments indicate that the communities were dominated by species with lower than average monoculture biomass. In the triculture, this effect was strong enough to cancel out the positive $\mathrm{CE}$, resulting in a negative NE. While the NE was positive in the bicultures, thus suggesting a positive effect of biodiversity, the additive partitioning of the triculture indicated that the production decreased with increasing plant species richness (Loreau \& Hector 2001).

\section{Biomass allocation patterns}

Biomass allocation patterns were most likely explained by exposure rather than interspecific interactions (Kautsky 1991, Boström et al. 2006). Potamogeton perfoliatus invested more into belowground parts than into shoots, while $P$. filiformis tended to show less variable R:S ratios (Kautsky 1988, 1991). The higher relative change in shoot density and aboveground biomass of $P$. filiformis compared to the other species suggests that exposed sandy bottoms represent optimal growing conditions for this species. In contrast, the performance of $P$. perfoliatus monocultures indicate that, despite the morphological plasticity of the species, sediment stability and shelter provided by other plants seem to be a prerequisite for successful population establishment and maintenance in harsh environments (Kautsky 1988, 1991). In a transplantation study in the Baltic Sea (Worm \& Reusch 2000), a similar pattern was recorded for young Zostera marina plants.

In temperate macrophytes, tuber and turion production is initiated when carbohydrate production exceeds growth demands, and usually peaks towards the end of the season (Santamaría \& Llano García 2004). In the present study, species richness correlated positively with tuber and turion abundance, implicating a coupling between interspecific competition and resource investment. As the number of propagules determines the initial density, and thus the ability of a species to 
compete for space, light and nutrients early in the following growth season (Kautsky 1990), Potamogeton filiformis and $P$. perfoliatus may possess a competitive advantage over other species.

\section{Ramet production and space occupation}

In terrestrial plant studies, aboveground and belowground space partitioning has been recorded, e.g. increasing shoot density and cover in mixtures relative to monocultures (Lorentzen et al. 2008). While establishment and ramet production in freshwater plants depends on nutrient status and population density (Wolfer \& Straile 2004), little is known about the importance of interspecific competition for space during plant succession in seagrass ecosystems (Williams 1990). Due to the differing repertoire of functional traits among the species studied here, space occupation patterns through clonal growth were species-specific, but not significantly influenced by species richness. However, the shoot density of Potamogeton filiformis tended to be higher in mixes compared to monocultures, while the linear increase in shoot density of $P$. perfoliatus only reflected an increase from a negative $(-61.4 \%)$ to slightly positive (8.5\%) level (Fig. 4, see 'Discussion' subsection 'Biomass allocation patterns'). In the study area, Zostera marina is a biomass storer with low productivity (Kautsky 1988, Boström et al. 2004) and space occupation appeared to be unaffected by the presence of other species. Based on a mesocosm study, the space occupation of $P$. perfoliatus was suggested to be negatively density-dependent (Wolfer \& Straile 2004), but such a pattern was not observed in the present study. The spatial spread of $P$. filiformis was highest in monocultures $(>60 \mathrm{~cm}$ ) compared to mixed cultures. Decreasing space occupation capacity in mixed communities can be explained by interspecific competition (Grime 2001); alternatively, complementarity in mixed communities may result in shorter rhizome spacer lengths and thus increased concentration and foraging ability of ramets in nutrient-rich patches (Wolfer 2008). However, sediment porewater nutrient levels were not significantly lower in the mixed communities, suggesting that interspecific competiton is more important (than complementarity) for space occupation capacity.

\section{Sediment porewater nutrients and resource use}

Plant richness did not markedly affect the sediment organic deposition and mineralization, thus the $\mathrm{C}: \mathrm{N}$ ratio did not differ between treatments. The low $\mathrm{C}: \mathrm{N}$ ratios found in the present study indicate that the organic mat- ter in the sediment is derived from benthic microalgae (as suggested by Hansen \& Kristensen 1998), as seagrass detritus generally has a higher C:N ratio (Kristensen \& Hansen 1995, Boschker et al. 2000). Because of differing biomass and penetration depth of rhizomes and roots (Potamogeton filiformis: slender roots, $\sim 5 \mathrm{~cm}$ depth, Zostera marina: extensive rhizomes and roots, $\sim 10 \mathrm{~cm}$ depth, P. perfoliatus: extensive rhizome, intermediate roots, $15 \mathrm{~cm}$ depth; authors' pers. obs.), we expected to record complementary resource use. As water column nutrients were depleted throughout the productive season at the study site, sediment nutrients likely constituted the main source of nutrients for the plant communities (Hemminga 1998). When Z. marina grows on sandy sediments it is often considered N-limited (Short 1987). This is in accordance with the $Z$. marina treatments, with average $\mathrm{NH}_{4}{ }^{+}$concentrations in porewater $<100 \mu \mathrm{M}$ (Fourqurean et al. 1992, present study). The highest porewater $\mathrm{NH}_{4}{ }^{+}$concentration was recorded in unvegetated control plots, while surprisingly, the triculture had the highest $\mathrm{NH}_{4}{ }^{+}$concentration among the plant treatments. Thus, in contrast to some terrestrial studies (e.g. Tilman et al. 1997), no resource use complementarity was recorded. This indicates weak richness effects on sediment porewater nutrient concentrations, i.e. plants in our mixed brackish water communities do not appear to use available nutrients more completely than in monocultures.

For some species, a more efficient nutrient use at high species richness has been recorded (van Ruijven \& Berendse 2005), which may also explain the observations in the present study. However, in the present study, the leaf nutrient content was not analyzed, so the exact mechanism behind this observation requires further study. In contrast to $\mathrm{NH}_{4}{ }^{+}, \mathrm{PO}_{4}{ }^{3-}$ levels did not differ between vegetated and unvegetated plots. Similar patterns have been recorded in the study area (Boström et al. 2004). Surprisingly, the $\mathrm{PO}_{4}{ }^{3-}$ concentration was highest in the biculture of Zostera marina and Potamogeton perfoliatus, suggesting that despite the non-significant CE found for biomass production, these species did not utilize porewater nutrients as efficiently as other species combinations.

\section{CONCLUSIONS}

Our results show that the effects of plant richness per se on primary production and resource use in brackish water plant communities are weak or non-existent. However, species composition appears to be important for both aboveground and belowground production in angiosperm communities. In earlier work (Engelhardt \& Ritchie 2002), richness responses of these plant compartments have not been analysed separately for indi- 
vidual component species. The present study shows that a substantial part of angiosperm species interactions occurs in the sediment, and that these interactions might differ from aboveground dynamics. Understanding the interactions in multispecific plant communities is challenging, but crucial for determining the consequences of species loss for the functioning of these valuable coastal ecosystems.

Acknowledgements. A. Hector, H. Setälä and J. Mikola provided valuable comments on the experimental design. M. Holmer is acknowledged for help with the C:N analysis. J. Nyström and E. Juslin assisted in the field and laboratory. Korpoström Archipelago Centre provided excellent working facilities. This study was conducted as a part of the project 'Biodiversity and Ecosystem Functioning Under Environmental Stress: Role of Biological Insurance in Aquatic Plant Communities' (C. Boström, Maj and Tor Nessling Foundation, Project 2008216). Additional funding was received from Societas Pro Fauna et Flora Fennica, the Riihi Foundation, the Åbo Akademi Foundation and the Swedish Cultural Foundation.

\section{LITERATURE CITED}

Bertness MD, Callaway R (1994) Positive interactions in communities. Trends Ecol Evol 9:191-193

Boschker HTS, Wielemaker A, Schaub BEM, Holmer M (2000) Limited coupling of macrophyte production and bacterial carbon cycling in the sediments of Zostera spp. meadows. Mar Ecol Prog Ser 203:181-189

Boström C, Baden S, Krause-Jensen D (2003) The seagrasses of Scandinavia and the Baltic Sea. In: Green EP, Short FT, Spalding MD (eds) World atlas of seagrasses: present status and future conservation. University of California Press, Berkeley, CA, p 27-37

Boström C, Roos C, Rönnberg O (2004) Shoot morphometry and production dynamics of eelgrass in the northern Baltic Sea. Aquat Bot 79:145-161

Boström C, O'Brien K, Roos C, Ekebom J (2006) Environmental variables explaining structural and functional diversity of seagrass macrofauna in an archipelago landscape. J Exp Mar Biol Ecol 335:52-73

Bruno JF, Boyer KE, Duffy JE, Lee SC, Kertesz JS (2005) Effects of macroalgal species identity and richness on primary production in benthic marine communities. Ecol Lett 8:1165-1174

Bruno JF, Lee SC, Kertesz JS, Carpenter RC, Long ZT, Duffy JE (2006) Partitioning effects of algal species identity and richness on benthic marine primary production. Oikos 115:170-178

> Caffrey JM, Kemp WM (1991) Seasonal and spatial patterns of oxygen production, respiration and root rhizome release in Potamogeton perfoliatus and Zostera marina. Aquat Bot 40:109-128

> Callaway RM, King L (1996) Temperature-driven variation in substrate oxygenation and the balance of competition and facilitation. Ecology 77:1189-1195

> Cardinale BJ, Nelson K, Palmer MA (2000) Linking species diversity to the functioning of ecosystems: on the importance of environmental context. Oikos 91:175-183

Cardinale BJ, Palmer MA, Collins SL (2002) Species diversity enhances ecosystem functioning through interspecific facilitation. Nature 415:426-429
Cardinale BJ, Wright JP, Cadotte MW, Carroll IT and others (2007) Impacts of plant diversity on biomass production increase through time because of species complementarity. Proc Natl Acad Sci USA 104:18123-18128

> Duarte CM (2000) Marine biodiversity and ecosystem services: an elusive link. J Exp Mar Biol Ecol 250:117-131

> Duarte CM, Terrados J, Agawin NSR, Fortes MD (2000) An experimental test of the occurrence of competitive interactions among SE Asian seagrasses. Mar Ecol Prog Ser 197: $231-240$

> Duffy JE (2006) Biodiversity and the functioning of seagrass ecosystems. Mar Ecol Prog Ser 311:233-250

Engelhardt AM, Ritchie ME (2002) The effect of aquatic plant species richness on wetland ecosystem processes. Ecology 83:2911-2924

> Fargione J, Tilman D (2005) Niche differences in phenology and rooting depth promote coexistence with a dominant $\mathrm{C}_{4}$ bunchgrass. Oecologia 143:598-606

Fourqurean JW, Zieman JC, Powell GVN (1992) Relationships between porewater nutrients and seagrasses in a subtropical carbonate environment. Mar Biol 114:57-65

Grime JP (2001) Plant strategies, vegetation processes, and ecosystem properties. John Wiley \& Sons, New York

Hansen K, Kristensen E (1998) The impact of the polychaete Nereis diversicolor and enrichment of macroalgal (Chaetomorpha linum) detritus on benthic metabolism and nutrient dynamics in organic-poor and organic-rich sediment. J Exp Mar Biol Ecol 231:201-223

Harper JL (1977) Population biology of plants. Academic Press, New York

Hector A, Schmid B, Beierkuhnlein C, Caldiera MC and others (1999) Plant diversity and productivity experiments in European grasslands. Science 286:1123-1127

> Hemminga MA (1998) The root/rhizome system of seagrasses: an asset and a burden. J Sea Res 39:183-196

Hooper DU (1998) The role of complementarity and competition in ecosystem responses to variation in plant diversity. Ecology 79:704-719

> Hooper DU, Dukes JS (2004) Overyielding among functional groups in a long-term experiment. Ecol Lett 7:95-105

> Hooper DU, Vitousek PM (1997) The effects of plant composition and diversity on ecosystem processes. Science 277:1302-1305

Hooper DU, Chapin FS III, Ewell JJ, Hector A and others (2005) Effects of biodiversity on ecosystem functioning: a consensus of current knowledge. Ecol Monogr 75:3-55

Kautsky L (1988) Life strategies of aquatic soft bottom macrophytes. Oikos 53:126-135

Kautsky L (1990) Seed and tuber banks of aquatic macrophytes in the Askö area, northern Baltic proper. Holarct Ecol 13:143-148

Kautsky L (1991) In situ experiments on the interrelationships between six brackish macrophyte species. Aquat Bot 39: 159-172

Kautsky L, Kautsky N (2000) The Baltic Sea, including Bothnian Sea and Bothnian Bay. In: Sheppard CRC (ed) Seas at the millennium: an environmental evaluation, Vol I. Regional chapters: Europe, The Americas and West Africa. Elsevier Science, Oxford, p 121-134

Kristensen E, Andersen FØ (1987) Determination of organic carbon in marine sediments: a comparison of two CHNanalyzer methods. J Exp Mar Biol Ecol 109:15-23

Kristensen E, Hansen K (1995) Decay of plant detritus in organicpoor marine sediment: production rates and stoichiometry of dissolved C and N compounds. J Mar Res 53:675-702

> Loreau M (1998) Separating sampling and other effects in biodiversity experiments. Oikos 82:600-602 
Loreau M (2000) Biodiversity and ecosystem functioning: recent theoretical advances. Oikos 91:3-17

Loreau M, Hector A (2001) Partitioning selection and complementarity in biodiversity experiments. Nature 412:72-76

Loreau M, Naeem S, Inchausti P, Bengtsson J and others (2001) Biodiversity and ecosystem functioning: current knowledge and future challenges. Ecology 294:804-808

Lorentzen S, Roscher C, Schumacher J, Schulze ED, Schmid B (2008) Species richness and identity affect the use of aboveground space in experimental grasslands. Perspect Plant Ecol Evol Syst 10:73-87

Moore TN, Fairweather PG (2006) Decay of multiple species of seagrass detritus is dominated by species identity, with an important influence of mixing litters. Oikos 114: 329-337

> Naeem S, Håkansson K, Lawton JH, Crawley MJ, Thompson LJ (1996) Biodiversity and plant productivity in a model assemblage of plant species. Oikos 76:259-264

Orth RJ, Carruthers TJB, Dennison WC, Duarte CM and others (2006) A global crisis for seagrass ecosystems. BioScience 56:987-996

Parker JD, Duffy JE, Orth RJ (2001) Plant species diversity and composition: experimental effects on marine epifaunal assemblages. Mar Ecol Prog Ser 224:55-67

Roscher C, Schumacher J, Weisser WW, Schmid B, Schulze ED (2007) Detecting the role of individual species for overyielding in experimental grassland communities composed of potentially dominant species. Oecologia 154: 535-549

Santamaría L, Llano García AI (2004) Latitudinal variation in tuber production in an acquatic pseudo-annual plant, Potamogeton pectinatus. Aquat Bot 79:51-64

Short FT (1987) Effects of sediment nutrients on seagrasses: literature review and mesocosm experiment. Aquat Bot 27:41-57

Sokal RR, Rohlf FJ (1994) Biometry: the principles and prac-

Submitted: May 5, 2009; Accepted: September 17, 2009 tice of statistics in biological research, 3rd edn. W. H. Freeman, New York

Solan M, Raffaelli DG, Paterson DM, White PCL, Pierce GJ (2006) Marine biodiversity and ecosystem function: empirical approaches and future research needs. Mar Ecol Prog Ser 311:175-178

- Srivastava DS, Vellend M (2005) Biodiverity-ecosystem function research: Is it relevant to conservation? Annu Rev Ecol Evol Syst 36:267-294

Stachowicz JJ, Bruno JF, Duffy JE (2007) Understanding effects of marine biodiversity on communities and ecosystems. Annu Rev Ecol Evol Syst 38:739-766

Tilman D (1999) The ecological consequences of changes in biodiversity: a search for general principles. Ecology 80: 1455-1474

Tilman D, Knops D, Wedin P, Reich M, Ritchie M, Sieman E (1997) The influence of functional diversity and composition on ecosystem processes. Science 277:1300-1302

van Ruijven J, Berendse F (2005) Diversity-productivity relationships: initial effects, long-term patterns, and underlying mechanisms. Proc Natl Acad Sci USA 102:695-700

Weigelt A, Schumacher J, Walther T, Bartelheimer M, Steinlein T, Beyschlag W (2007) Identifying mechanisms of competition in multispecies communities. J Ecol 95:53-64

Williams SL (1990) Experimental studies of Caribbean seagrass bed development. Ecol Monogr 60:449-469

Wolfer SR (2008) Clonal architecture and patch formation of Potamogeton perfoliatus L. in response to environmental conditions. PhD thesis, Wageningen University, Wageningen

Wolfer SR, Straile D (2004) Spatio-temporal dynamics and plasticity of clonal architecture in Potamogeton perfoliatus. Aquat Bot 78:307-318

Worm B, Reusch TBH (2000) Do nutrient availability and plant density limit seagrass colonization in the Baltic Sea? Mar Ecol Prog Ser 200:159-166

Proofs received from author(s): November 27, 2009 